\title{
Short-Term Effects of Low-Head Barrier Removals on Fish Communities and Habitats
}

OPEN ACCESS

Edited by:

Karl M. Wantzen,

Université de Tours, France

Reviewed by:

Matthew McCartney,

International Water Management

Institute, Sri Lanka

Juergen Geist,

Technical University of Munich,

Germany

*Correspondence:

Damian H. Bubb

damianbubb@paragonecology.co.uk

Martyn C. Lucas

m.c.lucas@durham.ac.uk

Specialty section:

This article was submitted to

Conservation and Restoration

Ecology,

a section of the journal

Frontiers in Ecology and Evolution

Received: 18 April 2021

Accepted: 08 October 2021

Published: 03 November 2021

Citation:

Bubb DH, Birnie-Gauvin K, Tummers JS, Aarestrup K, Jepsen N and Lucas MC (2021) Short-Term Effects of Low-Head Barrier Removals on Fish Communities and Habitats.

Front. Ecol. Evol. 9:697106 doi: 10.3389/fevo.2021.697106

\section{Damian H. Bubb' ${ }^{1 *}$ Kim Birnie-Gauvin ${ }^{2}$, Jeroen S. Tummers ${ }^{1,3}$, Kim Aarestrup $^{2}$, Niels Jepsen ${ }^{2}$ and Martyn C. Lucas ${ }^{1 *}$}

\begin{abstract}
' Department of Biosciences, University of Durham, Durham, United Kingdom, ${ }^{2}$ DTU Aqua, National Institute of Aquatic Resources, Section for Freshwater Fisheries Ecology, Technical University of Denmark, Silkeborg, Denmark, ${ }^{3}$ Reptile, Amphibian and Fish Conservation Netherlands, Nijmegen, Netherlands
\end{abstract}

Barrier removal is increasingly being seen as the optimal solution to restore lotic habitat and fish communities, however, evidence of its efficacy is often limited to single sites or catchments. This study used a before-after methodology to examine the shortterm (average, 541 days) effects of low-head $(0.1-2.9 \mathrm{~m})$ barrier removal at 22 sites distributed across Denmark and northern England on fish density, community, and river habitat responses. Following barrier removal, changes in the aquatic habitat were observed, such that the area immediately upstream of the former barrier location became shallower, with larger substrate and faster flow conditions. The reinstatement of this habitat was especially valuable in Danish streams, where these habitat features are rare, due to the naturally low gradients. Across all 22 sites fish species richness and diversity was similar before and after removal of barriers, likely because of the short study timescale (1-2 years). Across all sites combined, there was an increase in total fish density following barrier removal. A large increase in salmonid (Salmo trutta and Salmo salar) densities following barrier removal occurred at 7 out of 12 Danish sites. No similar response in salmonid density was observed at any of the UK sites which were mostly characterized by high channel gradients and short ponded zones. Two UK barrier removal sites showed marked increases in density of non-salmonid fish species. This study suggests that the removal of low-head barriers can be an effective method of restoring lotic habitats, and can lead to positive changes in fish density in the former ponded zone. The short-term effect of small barrier removal on the fish community is more variable and its effectiveness is likely to be determined by wider riverine processes.

Keywords: dam, fish assemblage, fish passage, habitat restoration, connectivity

\section{INTRODUCTION}

Fragmentation of habitat within stream networks has been recognized as a serious threat to the diversity, abundance, and persistence of a variety of aquatic species (Sheldon, 1988; Dunham et al., 1997; Khan and Colbo, 2008). Dams, weirs, culverts, and other in-stream obstacles fragment rivers and streams by altering habitat, interrupting longitudinal connectivity and can have major impacts on biodiversity, populations, and the functioning of river ecosystems (Mueller et al., 2011). Whilst 
much focus has historically been on large dams and barriers (Rosenberg et al., 2000; Freeman et al., 2003), the potential importance of small barriers $(<5 \mathrm{~m})$, such as weirs, culverts, and water gauging stations, is increasingly being recognized (Catalano et al., 2007; Burroughs et al., 2010; Belletti et al., 2020). Small barriers are highly abundant worldwide, though perhaps especially in Europe (Garcia De Leaniz, 2008; Jones et al., 2019; Belletti et al., 2020; Sun et al., 2020). Whilst in isolation, smaller barriers which often enable some fish passage under some flow conditions (Kemp and O'Hanley, 2010; Tummers et al., 2016) are often deemed to have fewer impacts on fish populations, their abundance and cumulative impact can make for widespread effects (Lucas and Baras, 2001; Cooke et al., 2005; Diebel et al., 2015; Tummers et al., 2016; Birnie-Gauvin et al., 2017a).

Small barriers are, by their nature, most common on smaller, low stream order watercourses (Jones et al., 2019; Sun et al., 2020). The extent of their effects on biota depends primarily on the changes they cause to stream habitat and connectivity. The ponding effect upstream of small barriers may be very localized if the stream gradient is steep, but much larger if stream gradient is low (Birnie-Gauvin et al., 2017a). The effect on connectivity depends particularly upon the location (Kemp and O'Hanley, 2010); a small barrier immediately upstream of a confluence may restrict access by migrating species, while the connectivity impact of multiple adjacent barriers is cumulative.

A range of fishway designs have been developed to mitigate the impact of in-stream structures on connectivity by aiding fish passage (Clay, 1995; Silva et al., 2018). However, their efficacy varies with design and they are not equally effective in both directions and for all species (Noonan et al., 2012; Foulds and Lucas, 2013). In contrast to mitigation through the installation of fishways, barrier removal reinstates hydrological connectivity, more natural habitats, sediment transport and the free movement of aquatic biota, and is increasingly being viewed as preferable from a conservation, fisheries, and river management perspective (Roni et al., 2008; Kemp and O'Hanley, 2010; Birnie-Gauvin et al., 2017b). Many small river barriers are obsolete but still remain in place, in part due to their historical and cultural significance and perceived insignificance in respect to river processes. In the long term, removal is cheaper than the cost of maintaining a barrier (Bellmore et al., 2017; Silva et al., 2018), but requires an initial investment of funds. The rate of barrier removal is increasing rapidly, especially in North America, but studies of the ecological effects of barrier removal remain sparse (Bellmore et al., 2017).

Studies on fish communities following the removal of small structures have largely shown ecologically positive responses (Burroughs et al., 2010; Birnie-Gauvin et al., 2017a; Poulos and Chernoff, 2017; Birnie-Gauvin et al., 2018, 2020; Sun et al., 2021). Thus far, however, river barrier removal studies have focused on single sites or single catchments. The aims of this study, undertaken across multiple catchments in Denmark and northern England, were to evaluate the changes in mesohabitats and to record short-term (mostly 1-2 years) responses in fish density and community composition after removal of small barriers in stream systems in a region climatically suitable for Atlantic salmon Salmo salar and brown trout Salmo trutta. We hypothesized that removal of barriers would return flow conditions in impounded reaches from lentic to lotic, increase the sediment particle size and increase the abundance and diversity of native stream fishes, especially rheophiles.

\section{MATERIALS AND METHODS}

\section{Study Sites}

The 22 barriers which were removed were distributed across northern England (10 sites) and the Jutland peninsula in Denmark (12 sites; Figure 1). All barriers at these sites were considered low-head barriers, varying in height between a culvert of $0.12 \mathrm{~m}$ vertical step height and a $2.9 \mathrm{~m}$ vertical weir. The barriers were of varying ages and had been constructed for a range of purposes. The Danish barriers were primarily associated with fish farms where weirs had been widely constructed to divert water into fish farming facilities. The barriers at the UK sites had been constructed for a range of purposes including water abstraction, road/pedestrian crossings and flow regulation.

The barriers studied were removed between 2014 and 2018. Site choice was limited by accessible sites where barriers were being removed and, as a result, river gradients, widths, and length of ponded zones varied considerably between sites (Table 1). At all sites except for DK10 and DK11, only the barrier was removed; reprofiling and/or remeandering of the river was not carried out following barrier removal. At DK10 and DK11 the stream was completely dug out and re-meandered following barrier removal. Barriers at sites UK3 and UK7 were at or close to the tidal limit; the remainder were exclusively in fresh, non-tidal water (Table 1).

\section{Methods}

This study examined only the responses in habitat and fish densities in the impounded zone immediately upstream of barriers; although there may be further effects more distant from removed barriers these were not considered. At each of the 22 barrier sites, the in-stream habitat and fish community immediately upstream (from the barrier site to between 38 and $80 \mathrm{~m}$ upstream) of the barrier were evaluated prior to and after barrier removal [Mean (range): Before 382 (2-1065) days and After 541 (244-867) days]. Pre-removal surveys were undertaken between 16 May and 14 October with most (82\%) surveys carried out August-October. Surveys carried out before August were conducted then as it was the only opportunity to carry out a survey before the barrier was removed. Post-removal surveys were undertaken between 21 June and 28 October with 95\% carried out August-October. Most sites had an additional intermediate survey after barrier removal $[n=19$; Mean (range): 155 (3-403) days], which were carried out between 26 June and 17 October with $91 \%$ carried out August-October. All surveys were undertaken during base flow conditions, when water clarity was high.

\section{Habitat Measurements}

At each site, a river habitat survey of substrate, flow, and depth was completed as outlined by the Scottish Fisheries Co-Ordination Centre (SFCC, 2007) methodology. The riverbed 


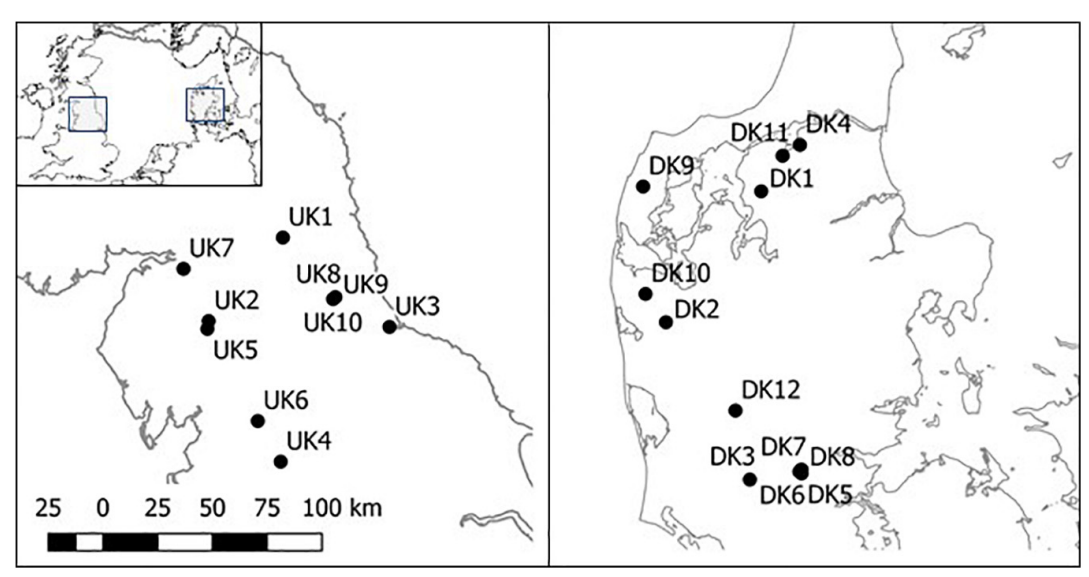

FIGURE 1 | Location of sites in northern England (UK1-UK10) and Denmark (DK1-DK12).

TABLE 1 | Site characteristics and details of barriers removed.

\begin{tabular}{|c|c|c|c|c|c|c|c|c|c|}
\hline Site & River catchment & Barrier type & $\begin{array}{l}\text { Head at } \\
\text { Q95 (m) }\end{array}$ & $\begin{array}{l}\text { River width } \\
\text { post removal } \\
\text { (m) }\end{array}$ & $\begin{array}{l}\text { Length of } \\
\text { ponded zone } \\
\text { (m) }\end{array}$ & $\begin{array}{l}\text { Distance from } \\
\text { sea }(\mathbf{k m})\end{array}$ & $\begin{array}{l}\text { Stream } \\
\text { order }\end{array}$ & Removal date & $\begin{array}{c}\text { Cost of } \\
\text { removal } \\
\text { (€K) }\end{array}$ \\
\hline DK1 & Trend Dambrug & Vertical weir & 1.4 & 4.5 & 1230 & 10.9 & 1 & $30 / 08 / 2017$ & $80^{*}$ \\
\hline DK3 & Risbøl Dambrug & Vertical weir & 0.91 & 5.1 & 300 & 52.3 & 2 & $28 / 06 / 2018$ & $283^{*}$ \\
\hline DK4 & Gelstrup Dambrug & Vertical weir & 1.33 & 6 & 1000 & 7.1 & 1 & $01 / 05 / 2018$ & $469^{*}$ \\
\hline DK5 & Refsgårdslund Dambrug & Vertical weir & 0.3 & 5.5 & 300 & 22.6 & 2 & $15 / 10 / 2017$ & $241^{*}$ \\
\hline DK7 & Gl. Potkær Fiskeri & Vertical weir & 1.8 & 1.3 & 280 & 24.6 & 2 & $01 / 09 / 2018$ & $67^{*}$ \\
\hline DK8 & Ny Potkær Fiskeri & Vertical weir & 2.6 & 1.4 & 250 & 24.2 & 2 & $01 / 04 / 2018$ & $67^{*}$ \\
\hline DK9 & Nørhå Fiskeri & Vertical weir & 1.4 & 4.8 & 2500 & 10.4 & 3 & $15 / 08 / 2018$ & $261^{*}$ \\
\hline DK10‘ & Øster Ørts Dambrug & Vertical weir & 1.5 & 4 & 600 & 22.9 & 1 & $01 / 03 / 2018$ & $201^{*}$ \\
\hline DK11 & Vidkær Dambrug & Vertical weir & 2.9 & 2.6 & 1500 & 1.2 & 1 & $01 / 12 / 2017$ & $201^{*}$ \\
\hline DK12 & Clasonsborg & Vertical weir & 2 & 7.7 & 2000 & 49 & 2 & $19 / 12 / 2018$ & $562^{*}$ \\
\hline UK4 & R. Aire & Vertical weir $\times 2$ & 0.3 & 9 & 47 & 131.4 & 4 & $18 / 06 / 2018$ & 10 \\
\hline UK5 & R. Lowther & Vertical weir & 0.4 & 16.1 & 55 & 82.6 & 6 & $14 / 08 / 2017$ & 149 \\
\hline UK6 & R. Ribble & Vertical weir & 0.7 & 8.1 & 46 & 119.4 & 4 & $12 / 06 / 2017$ & 4 \\
\hline UK7 & R. Caldew & Vertical weir & 0.5 & 21.2 & 67 & 36.3 & 5 & $30 / 06 / 2016$ & 33 \\
\hline UK8 & R. Deerness & $\begin{array}{l}\text { Multi-pipe-culvert } \\
\text { Crossing }\end{array}$ & 0.12 & 3.5 & 12 & 64.9 & 2 & $01 / 04 / 2014$ & $90^{\$}$ \\
\hline UK9 & R. Deerness & $\begin{array}{l}\text { Multi-pipe-culvert } \\
\text { Crossing }\end{array}$ & 0.15 & 2.9 & 17 & 65.1 & 2 & $01 / 04 / 2014$ & $90^{\$}$ \\
\hline UK10 & R. Deerness & $\begin{array}{l}\text { Multi-pipe-culvert } \\
\text { Crossing }\end{array}$ & 0.14 & 3 & 27 & 67.2 & 2 & 01/08/2014 & $57^{\$}$ \\
\hline
\end{tabular}

DK refers to Danish sites and UK refers to sites in northern England.

*Includes cost of payment of compensation to barrier owner.

$\$$ Includes cost of bridge to replace road crossing.

substrate composition, flow, and depth was visually assessed, with a proportion assigned to each category. The riverbed substrate was assessed using seven categories divided using an approximation of the Wentworth scale; (1) silt $(<0.06 \mathrm{~mm}),(2)$ sand $(0.06-2 \mathrm{~mm}),(3)$ gravel $(2-16 \mathrm{~mm})$, (4) pebble $(16-64 \mathrm{~mm})$, (5) cobble (64-246 mm), (6) boulder (>256 mm), and (7) bedrock (continuous rock surface). Flow was assessed using the following eight categories; (1) still marginal, (2) deep pool, (3) shallow pool, (4) deep glide, (5) shallow glide, (6) run, (7) riffle, and (8) torrent. Depth was divided into four categories; (1) 0-20 cm, (2) $21-40 \mathrm{~cm}$, (3) $41-80 \mathrm{~cm}$, and (4) $>80 \mathrm{~cm}$.

An index was calculated for depth, substrate and flow from the varying proportions of the categories recorded at each site. The indexes for depth, substrate, and flow was calculated from 
the sum of the proportion cover of each category (n) multiplied by the category (c) -1 /number of categories (s) -1 .

$$
\mathrm{I}=\sum \frac{n(c-1)}{s-1}
$$

The substrate index ranges from 0 (100\% silt) to $1(100 \%$ bedrock) with increasing particle size; the flow index from 0 (100\% still marginal) to 1 (100\% torrent) with increasing flow and the depth index from $0(100 \% 0-20 \mathrm{~cm})$ to $1(100 \%>80 \mathrm{~cm})$ with increasing depth.

\section{Fish Community Surveys}

To determine fish community composition, total fish species richness (number of fish species per sample), species diversity (Shannon-Wiener Index; Magurran, 2004), and (total) fish species density, quantitative depletion electric fishing was performed. Fish communities were surveyed via two- or threepass electric fishing depletion, over a distance of between 38 and $80 \mathrm{~m}$ across the full width of the stream channel. All the DK sites and UK7 were fished via two pass electric fishing with the remaining sites surveyed with three passes. Fish were sampled by electric fishing using wading with a single anode with a bankside generator and control box (Honda EU10i, Electracatch WFC1, $\sim 200 \mathrm{~V}$ for UK sites; 60 II G, $\sim 300 \mathrm{~V}$ for DK sites). For UK sites, $4 \mathrm{~mm}$ mesh stopnets were used to delimit the fished section. Fish removed from each pass were kept in separate aerated containers, and the catches processed after electric fishing had been completed. Fish were identified and measured for total length. Processed fish were released back to the capture location.

Fish densities per site were calculated according to Carle and Strub (1978) K-pass removal method by using the R programming language ( $\mathrm{R}$ Core Team, 2017), using package "FSA" (Ogle et al., 2021) for sites fished with three passes. For two pass electric fishing surveys the methodology of Lockwood and Schneider (2000) was used to calculate densities. Fish species diversity before and after barrier removal was examined using the Shannon-Wiener Index (using R package “vegan”). For tests of differences before and after barrier removal, Wilcoxon Signed

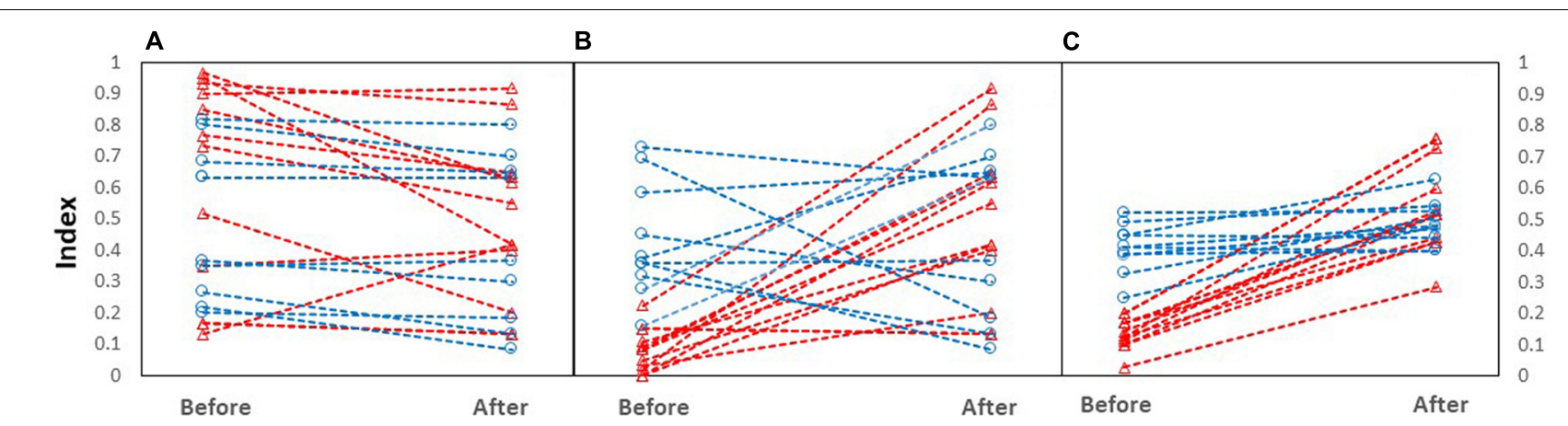

FIGURE 2 | Index of (A) depth, (B) substrate, and (C) flow before and after barrier removal. Red triangle symbols depict DK sites; blue circles depict UK sites.

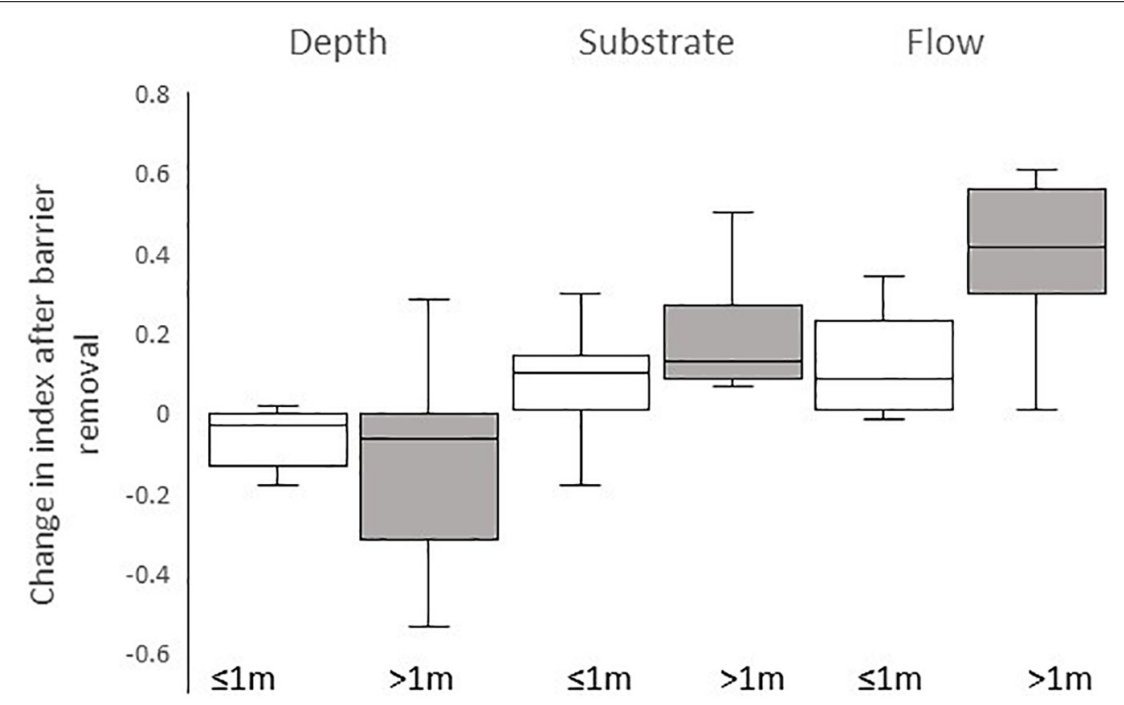

FIGURE 3 | Boxplots of change in index of depth, substrate size, and flow following barrier removal at sites with head loss of $\leq 1 \mathrm{~m}$ (white boxes) and head loss of $>1 \mathrm{~m}$ (gray boxes). The line within each box represents median change in index, ends of boxes represent the 25th and 75th percentiles, and whiskers represent the 10th and 90th percentiles. 
Rank (matched pairs) tests and Mann-Whitney $U$ tests were performed, following tests of normality (Kolmogorov-Smirnov), using an $\alpha$ level of significance of 0.05 .

\section{RESULTS}

\section{Habitat Measurements}

Following stream barrier removal, the section immediately upstream of the former barrier location became shallower, with larger substrate and increased flow, though sites varied individually in responses, especially in the United Kingdom (Figure 2). The index of depth decreased between pre- and post-removal measurements $(Z=-2.8 ; P=0.005)$. The index of substrate increased following barrier removal $(Z=-2.55$; $P=0.011)$ as did the index of flow $(Z=-3.9 ; P<0.001)$.

The removal of the smaller barriers (head $<1 \mathrm{~m}$ ) had less impact on the habitat variables measured, with less change in depth, substrate, and flow following barrier removal (Figure 3). The change was not significant in the case of depth $(U=49$; $P>0.05)$ and substrate $(U=35.5 ; P>0.05)$ but a significant difference was found in the change in flow index between larger barriers $(>1 \mathrm{~m})$ and smaller barriers $(U=12.5$; $P=0.002)$.

The ponded lengths in UK sites were, with one exception (UK3), an order of magnitude lower than at Danish sites. There was no significant change in wetted width before and after barrier removal $(Z=-1.48 ; P>0.05)$.

\section{Fish Community Surveys}

The DK sites were characterized by lower species richness than the UK sites (DK Before; Mean = 1.92, SD 0.79, DK After;
Mean $=1.50$, SD 1.38, UK Before; Mean $=4.90$, SD 1.73, and UK After; Mean $=4.50$, SD 1.43) and lower fish diversity (DK Before; Mean $=0.30$, SD 0.24, DK After; Mean $=0.21$, SD 0.34, UK Before; Mean $=1.04$, SD 0.29, and UK After; Mean = 1.17, SD 0.30). Across all sites combined there was no difference between the fish species richness $(Z=-1.19 ; P>0.05)$ or Shannon-Wiener Index $(Z=-0.071 ; P>0.05)$ before and after barrier removal. The DK sites were dominated by salmonids (Mean proportion; Before 0.75, After 0.89). Whilst salmonids were recorded at 9 out of 10 of the UK sites they constituted a smaller proportion (Mean proportion; Before 0.37, After 0.28) of the fish community.

There was a significant difference in fish density when comparing total fish density before and after barrier removal (paired test $Z=-4.11 ; P<0.001$ ). Pre-removal fish density was lower (Mean 0.37 fish $\mathrm{m}^{-2}$ SD 0.37 ) than the density postremoval (Mean 1.58 fish $\mathrm{m}^{-2} \mathrm{SD} 2.52$ ). Although mean densities increased after barrier removal across all sites combined, an increase was not observed at all sites, and there was considerable variation in the changes in fish density between sites (Figure 4 and Table 2).

There were large increases in fish density at seven of the 12 DK sites and 2 of the UK sites. The increase in densities at the DK sites were due to large increases in local salmonid abundance following barrier removal (Figure 5). In the United Kingdom, the increases in fish density were not caused by changes in salmonid abundance, but by increases in eel (Anguilla anguilla), flounder (Platichthys flesus), and stickleback (Gasterosteus aculaeatus) at site UK3, and increases in bullhead [Cottus perifretum, part of the C. gobio species complex (Freyhof et al., 2005)], minnow (Phoxinus phoxinus), and stone loach (Barbatula barbatula) at site UK4 (Figure 6).

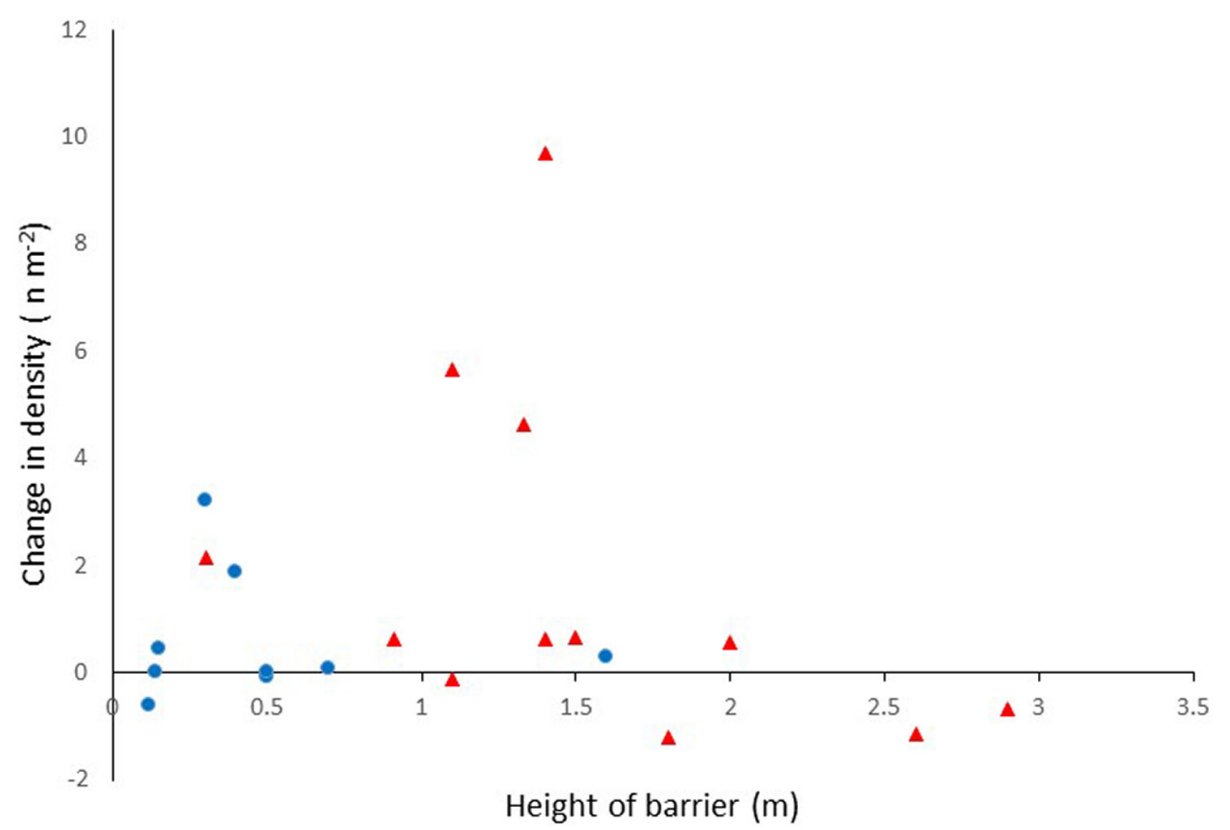

FIGURE 4 | Change in total fish density following barrier removal. Red triangles depict DK sites; blue circles depict UK sites. 

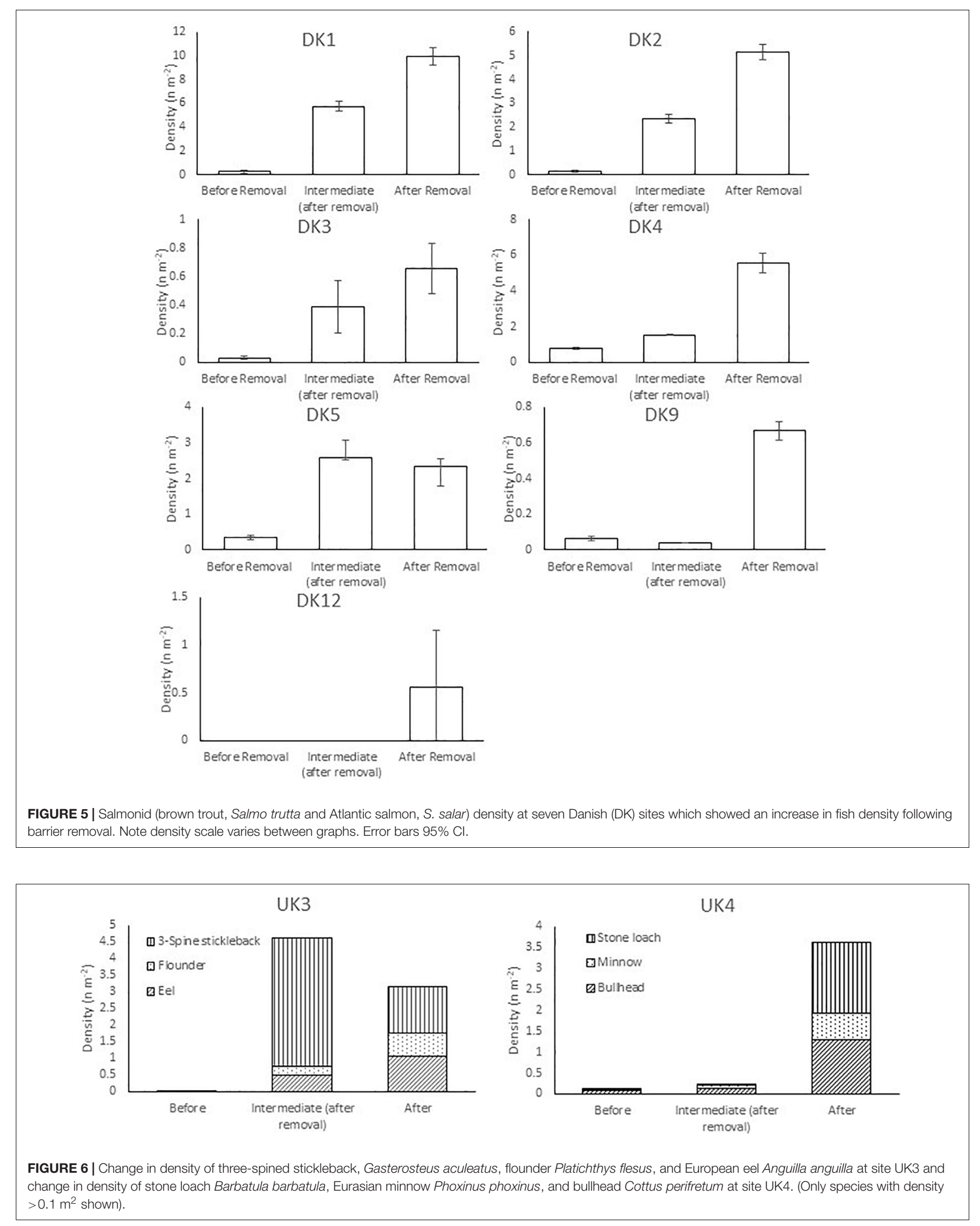
TABLE 2 | Fish species richness, Shannon-Wiener Index, total fish density, and salmonid density recorded before and after barrier removal.

\begin{tabular}{|c|c|c|c|c|c|c|c|c|}
\hline \multirow[t]{2}{*}{ Site } & \multicolumn{2}{|c|}{ Fish species richness } & \multicolumn{2}{|c|}{ Shannon-Wiener Index } & \multicolumn{2}{|c|}{ Total fish density $\left(\mathrm{n} \mathrm{m}^{-2}\right)$} & \multicolumn{2}{|c|}{ Salmonid density $\left(\mathrm{n} \mathrm{m}^{-2}\right)$} \\
\hline & Before & After & Before & After & Before & After & Before & After \\
\hline DK1 & 2 & 2 & 0.374 & 0.028 & 0.313 & 9.991 & 0.266 & 9.938 \\
\hline DK2 & 2 & 4 & 0.508 & 0.542 & 0.152 & 5.816 & 0.152 & 5.146 \\
\hline DK3 & 1 & 1 & 0 & 0 & 0.033 & 0.658 & 0.033 & 0.658 \\
\hline DK4 & 4 & 1 & 0.433 & 0 & 0.902 & 5.547 & 0.797 & 5.547 \\
\hline DK5 & 2 & 2 & 0.163 & 0.235 & 0.356 & 2.506 & 0.345 & 2.329 \\
\hline DK6 & 1 & 0 & 0 & $\mathrm{n} / \mathrm{a}$ & 0.106 & 0.000 & 0.000 & 0.000 \\
\hline DK7 & 2 & 1 & 0.52 & 0 & 1.216 & 0.020 & 0.940 & 0.020 \\
\hline DK8 & 2 & 0 & 0.658 & $\mathrm{n} / \mathrm{a}$ & 1.129 & 0.000 & 0.692 & 0.000 \\
\hline DK9 & 2 & 2 & 0.336 & 0.133 & 0.071 & 0.686 & 0.064 & 0.667 \\
\hline DK10 & 1 & 1 & 0 & 0 & 0.142 & 0.808 & 0.142 & 0.073 \\
\hline DK11 & 2 & 1 & 0.072 & 0 & 0.781 & 0.100 & 0.771 & 0.100 \\
\hline DK12 & 2 & 4 & 0.562 & 0.985 & 0.007 & 0.569 & 0.000 & 0.563 \\
\hline UK1 & 3 & 5 & 0.68 & 1.28 & 0.346 & 0.289 & 0.264 & 0.123 \\
\hline UK2 & 6 & 5 & 1.37 & 1.44 & 0.207 & 0.112 & 0.107 & 0.066 \\
\hline UK3 & 4 & 5 & 0.55 & 1.16 & 0.051 & 3.260 & 0.000 & 0.000 \\
\hline UK4 & 6 & 4 & 1.25 & 1.06 & 0.113 & 1.983 & 0.007 & 0 \\
\hline UK5 & 5 & 4 & 1.42 & 1.21 & 0.111 & 0.169 & 0.044 & 0.085 \\
\hline UK6 & 4 & 4 & 1.06 & 1.05 & 0.483 & 0.475 & 0.000 & 0.049 \\
\hline UK7 & 9 & 8 & 1.2 & 1.83 & 0.882 & 0.254 & 0.006 & 0.009 \\
\hline UK8 & 4 & 3 & 1.05 & 0.85 & 0.348 & 0.791 & 0.196 & 0.260 \\
\hline UK9 & 4 & 4 & 1 & 1.15 & 0.325 & 0.344 & 0.211 & 0.157 \\
\hline UK10 & 4 & 3 & 0.83 & 0.74 & 0.161 & 0.448 & 0.126 & 0.184 \\
\hline
\end{tabular}

"Before" measurements were made an average of 382 days before barrier removal; "After" measurements were made an average of 541 days after barrier removal.

\section{DISCUSSION}

This is one of the first studies to report on the effects of removal of small barriers across multiple catchments, albeit over a short time scale and in the immediate upstream locality of the former barrier. Previously reported studies have predominantly focused on the effects of single barriers (Birnie-Gauvin et al., 2017a; Poulos and Chernoff, 2017; Sun et al., 2021) or multiple barriers within the same catchment (Birnie-Gauvin et al., 2018, 2020; Sun et al., 2022). Results of this study show, as hypothesized, that removal of barriers can have a positive impact on lotic habitat and fish density at some sites. This adds to the growing evidence that barrier removal can be an effective measure for stream conservation (Burroughs et al., 2010; Hitt et al., 2012; Birnie-Gauvin et al., 2018, 2020; Sun et al., 2021, 2022). The strongest positive effect was recorded at some of the Danish sites, which showed large rapid increases in salmonid density following barrier removal. These changes are likely to be due to a combination of enhanced connectivity of the studied reach, and restoration of high-quality habitats such as fast-flowing water. Prior to removal, the sites were characterized by deeper water, silty, and sandy substrate with low coverage of gravel-like substrate. Following the removal of the barriers, the sites had lower water depth, an increase in gravel, pebble, and cobble and a significant increase in glides, runs, and riffles. These habitat changes reflect the restoration of the natural rheophilic habitat previously present. In the context of the wider river environment, the removal of the barriers and restoration of rheophilic habitats is especially important in Denmark, where these habitats are naturally limited due to low gradient in the landscape (BirnieGauvin et al., 2017a). Species like brown trout and Atlantic salmon are native rheophilic species, reliant on fast-moving and highly oxygenated water to thrive, especially during spawning and early development, and appeared to benefit significantly from the restoration of this habitat. Short term responses of fish species in northern English rivers were more complicated. In most cases total fish abundance did not change and the fish community remained similar. In some cases the response seemed to be barrier height and habitat-change dependent. For example, removal of a tidal limit weir (UK3) caused a dramatic increase in abundance of several less rheophilic species such as threespined stickleback, Gasterosteus aculeatus, flounder P. flesus, and European eel A. anguilla, but removal of a $0.5 \mathrm{~m}$ barrier at UK7, close to the tidal limit, altered the fish community little and resulted in a short-term reduction in abundance. While both barrier removals enabled direct access for fish, the former generated a much stronger habitat transition than the latter.

Whilst this study showed that removal of small barriers can be beneficial for fish density upstream of the barriers, this response was not observed across all sites. Many of the UK sites and some of the Danish sites did not show any positive change in fish density. The lack of a response recorded at these sites could be a reflection of several factors. Many of the smaller barriers studied are likely to only have represented a partial barrier to fish movements (Tummers et al., 2016) and the changes in habitat at the smaller barriers $(<1 \mathrm{~m})$ were comparatively small. The 
ponded lengths in UK sites were, with one exception (UK3) an order of magnitude lower than at Danish sites and so the effect on habitat response, and potentially on fish community change, was smaller for most UK sites. This study only considered the removal of the barrier in isolation and only over an ecologically narrow time frame; the wider dynamics of the fish populations in the rivers studied, interactions between different stretches, or impacts of other barriers present in the system were not considered here, but are likely important. Most fish communities are simultaneously impacted by multiple interacting anthropologic pressures (Geist and Hawkins, 2016; Mueller et al., 2020), the removal of barriers may mitigate one stressor but a consideration of other factors may be required for restoration of fish populations. Stream recovery may only occur following barrier removal over longer time periods (Doyle et al., 2005; Maloney et al., 2008; Sun et al., 2022) than the short time scale of this study. In addition the limited sampling before and after barrier removal carried out in this study precludes the identification of the extent of stochastic temporal variability between years in fish abundance and ability to account for this. The differences suggest that the strongest improvements derived from low-head barrier removal are likely to be achieved when barriers of 1-2 $\mathrm{m}$ are removed at sites that have relatively low gradient, but which are not impacted by other factors (Mueller et al., 2020; Geist, 2021) such as poor water quality and have good potential for habitat restoration. Single obstacles that are near key sites such as confluences and which open long stretches of natural habitat are likely to have strong positive restoration effects far beyond the specific site (Hitt et al., 2012). In contrast, where there are many small barriers $(<0.5 \mathrm{~m})$ in a stream with moderate gradients (as was the case for most of the barriers removed in

\section{REFERENCES}

Belletti, B., Garcia de Leaniz, C., Jones, J., Bizzi, S., Börger, L., Segura, S., et al. (2020). More than one million barriers fragment Europe's rivers. Nature 588, 436-441. doi: 10.1038/s41586-020-3005-2

Bellmore, J. R., Duda, J. J., Craig, L. S., Greene, S. L., Torgersen, C. E., Collins, M. J., et al. (2017). Status and trends of dam removal research in the United States. Wires Water 4:e1164. doi: 10.1002/wat2.1164

Birnie-Gauvin, K., Candee, M. M., Baktoft, H., Larsen, M. H., Koed, A., and Aarestrup, K. (2018). River connectivity reestablished: effects and implications of six weir removals on brown trout smolt migration. River Res. Appl. 34, 548-554. doi: 10.1002/rra.3271

Birnie-Gauvin, K., Nielsen, J., Frandsen, S. B., Olsen, H.-M., and Aarestrup, K. (2020). Catchment-scale effects of river fragmentation: a case study on restoring connectivity. J. Environ. Manag. 264:110408. doi: 10.1016/j.jenvman.2020. 110408

Birnie-Gauvin, K., Aarestrup, K., Riis, T. M. O., Jepsen, N., and Koed, A. (2017a). Shining a light on the loss of rheophilic fish habitat in lowland rivers as a forgotten consequence of barriers, and its implications for management. Aquatic Conserv. Mar. Freshw. Ecosyst. 27, 539, 1345-1349. doi: 10.1002/aqc. 2795

Birnie-Gauvin, K., Tummers, J. S., Lucas, M. C., and Aarestrup, K. (2017b). Adaptive management in the context of barriers in European freshwater ecosystems. J. Environ. Manag. 204, 436-441. doi: 10.1016/j.jenvman.2017.0 9.023

Burroughs, B. A., Hayes, D. B., Klomp, K. D., Hansen, J. F., and Mistak, J. (2010). The Effects of the Stronach Dam removal on fish in the Pine River, Manistee northern England), removal of individual barriers may not have an immediate effect, and changes to more natural conditions and positive impacts on the fish community may only be seen after the removal of multiple obstacles (Sun et al., 2022).

\section{DATA AVAILABILITY STATEMENT}

The raw data supporting the conclusions of this article will be made available by the authors, without undue reservation.

\section{AUTHOR CONTRIBUTIONS}

ML, KA, and NJ conceived and designed the study. KB-G and JT led the field work in Denmark and England, respectively. DB and $\mathrm{KB}-\mathrm{G}$ analyzed the data and led the writing of the manuscript. All co-authors commented on and agreed the manuscript.

\section{FUNDING}

This work was funded by the European Union AMBER (Adaptive Management of Barriers in European Rivers) project (Grant Number 689682).

\section{ACKNOWLEDGMENTS}

We are grateful to Atticus Albright, Jingrui Sun, and Andreas Svarer for assistance with fieldwork.

County, Michigan. Trans. Am. Fish. Soc. 139, 1595-1613. doi: 10.1577/T09056.1

Carle, F. L., and Strub, M. R. (1978). A new method for estimating population size from removal data. Biometrics 34, 621-630. doi: 10.2307/2530381

Catalano, M. J., Bozek, M. A., and Pellett, T. D. (2007). Effects of dam removal on fish assemblage structure and spatial distributions in the Baraboo River, Wisconsin. North Am. J. Fish. Manag. 27, 519-530. doi: 10.1577/M06-001.1

Clay, C. H. (1995). Design of Fishways and Other Fish Facilities, 2nd Edn. Boca Raton, FL: CRC Press.

Cooke, S. J., Bunt, C. M., Hamilton, S. J., Jennings, C. A., Pearson, M. P., Cooperman, M. S., et al. (2005). Threats, conservation strategies, and prognosis for suckers (Catostomidae) in North America: insights from regional case studies of a diverse family of non-game fishes. Biol. Conserv. 121, 317-331. doi: 10.1016/j.biocon.2004.05.015

Diebel, M. W., Fedora, M., Cogswell, S., and O’Hanley, J. R. (2015). Effects of road crossings on habitat connectivity for stream-resident fish. River Res. Appl. 31, 1251-1261. doi: 10.1002/rra.2822

Doyle, M. W., Stanley, E. H., Orr, C. H., Selle, A. R., Sethi, S. A., and Harbor, J. M. (2005). Stream ecosystem response to small dam removal: lessons from the Heartland. Geomorphology 71, 227-244. doi: 10.1016/j.geomorph.2004.0 4.011

Dunham, J. B., Vinyard, G. L., and Rieman, B. E. (1997). Habitat fragmentation and extinction risk of Lahontan cutthroat trout. North Am. J. Fish. Manag. 17, 910-917. doi: 10.1577/1548-8675(1997)017<1126:HFAERO>2.3.CO;2

Foulds, W. L., and Lucas, M. C. (2013). Extreme inefficiency of two conventional, technical fishways used by European river lamprey (Lampetra fluviatilis). Ecol. Eng. 58, 423-433. doi: 10.1016/j.ecoleng.2013.06.038 
Freeman, M. C., Pringle, C. M., and Greathouse, E. A. (2003). Ecosystem-level consequences of migratory faunal depletion caused by dams. Am. Fish. Soc. Symp. 35, 255-266.

Freyhof, J., Kottelat, M., and Nolte, A. (2005). Taxonomic diversity of European Cottus with description of eight new species (Teleostei: Cottidae). Ichthyol. Explor. Freshw. 16, 107-172.

Garcia De Leaniz, C. (2008). Weir removal in salmonid streams: implications, challenges and practicalities. Hydrobiologia 609, 83-96. doi: 10.1007/s10750008-9397-x

Geist, J. (2021). Editorial: green or red: challenges for fish and freshwater biodiversity conservation related to hydropower. Aquatic Conserv. Mar. Freshw. Ecosyst. 31, 1551-1558. doi: 10.1002/aqc.3597

Geist, J., and Hawkins, S. J. (2016). Habitat recovery and restoration in aquatic ecosystems; current progress and future challenges: aquatic restoration. Aquatic Conserv. Mar. Freshw. Ecosyst. 26, 942-962. doi: 10.1002/aqc.2702

Hitt, N. P., Eyler, S., and Wofford, J. E. B. (2012). Dam removal increases American eel abundance in distant headwater streams. Trans. Am. Fish. Soc. 141, 11711179. doi: 10.1080/00028487.2012.675918

Jones, J., Börger, L., Tummers, J., Jones, P., Lucas, M., Kerr, J., et al. (2019). A comprehensive assessment of stream fragmentation in Great Britain. Sci. Total Environ. 631, 756-762. doi: 10.1016/j.scitotenv.2019.04.125

Kemp, P. S., and O'Hanley, J. R. (2010). Procedures for evaluating and prioritising the removal of fish passage barriers : a synthesis. Fish. Manag. Ecol. 17, 297-322. doi: 10.1111/j.1365-2400.2010.00751.x

Khan, B., and Colbo, M. H. (2008). The impact of physical disturbance on stream communities: lessons from road culverts. Hydrobiologia 600, 229-235. doi: 10.1007/s10750-007-9236-5

Lockwood, R. N., and Schneider, J. C. (2000). "Chapter 7: stream fish population estimates by mark-and-recapture and depletion methods," in Manual of Fisheries Survey Methods II: with Periodic Updates Fisheries Special Report 25, ed. J. Schneider (Ann Arbor, MI: Michigan Department of Natural Resources).

Lucas, M. C., and Baras, E. (2001). Migration of Freshwater Fishes. Oxford: Blackwell Science Ltd. doi: 10.1002/9780470999653

Magurran, A. E. (2004). Measuring Biological Diversity. Oxford: Blackwell Science Ltd.

Maloney, K. O., Dodd, H., Butler, S. E., and Wahl, D. H. (2008). Changes in macroinvertebrate and fish assemblages in a medium-sized river following a breach of a low-head dam. Freshw. Biol. 53, 1055-1068. doi: 10.1111/j.13652427.2008.01956.x

Mueller, M., Bierschenk, A. M., Bierschenk, B. M., Pander, J., and Geist, J. (2020). Effects of multiple stressors on the distribution of fish communities in 203 headwater streams of Rhine, Elbe and Danube. Sci. Total Environ. 703:134523. doi: 10.1016/j.scitotenv.2019.134523

Mueller, M., Pander, J., and Geist, J. (2011). The effects of weirs on structural stream habitat and biological communities. J. Appl. Ecol. 48, 1450-1461. doi: 10.1111/j.1365-2664.2011.02035.x

Noonan, M. J., Grant, J. W. A., and Jackson, C. D. (2012). A quantitative assessment of fish passage efficiency. Fish Fish. 13, 450-464. doi: 10.1111/j.1467-2979.2011. 00445.x

Ogle, D. H., Doll, J. C., Wheeler, P., and Dinno, A. (2021). FSA: Fisheries Stock Analysis. R package version 0.9.1. Available online at: https://github.com/ droglenc/FSA
Poulos, H. M., and Chernoff, B. (2017). Effects of dam removal on fish community interactions and stability in the Eightmile River system, Connecticut, USA. Environ. Manag. 59, 249-263. doi: 10.1007/s00267-016-0794-z

R Core Team (2017). R: A Language and Environment for Statistical Computing. Vienna: R Foundation for Statistical Computing.

Roni, P., Hanson, K., and Beechie, T. (2008). Global review of the physical and biological effectiveness of stream habitat rehabilitation techniques. North Am. J. Fish. Manag. 28, 856-890. doi: 10.1577/M06-169.1

Rosenberg, D. M., McCully, P., and Pringle, C. M. (2000). Global-scale environmental effects of hydrological alterations: introduction. BioScience 50, 746-751. doi: 10.1641/0006-3568(2000)050[0746:GSEEOH]2. $0 . \mathrm{CO} ; 2$

SFCC (2007). Habitat Surveys Manual. Pitlochry: Scottish Fisheries Co-ordination Centre.

Sheldon, A. L. (1988). Conservation of stream fishes: patterns of diversity, rarity and risk. Conserv. Biol. 2, 149-156. doi: 10.1111/j.1523-1739.1988.tb00 166.x

Silva, A. T., Lucas, M. C., Castro-Santos, T., Katopodis, C., Baumgartner, L. J., Thiem, J. D., et al. (2018). The future of fish passage science, engineering, and practice. Fish Fish. 19, 340-362. doi: 10.1111/faf.12258

Sun, J., Galib, S. M., and Lucas, M. C. (2020). Are national barrier inventories fit for stream connectivity restoration needs? A test of two catchments. Water Environ. J. 34, 791-803. doi: 10.1111/wej.12578

Sun, J., Galib, S. M., and Lucas, M. C. (2021). Rapid response of fish and aquatic habitat to removal of a tidal barrier. Aquatic Conserv. Mar. Freshw. Ecosyst. 31, 1802-1816. doi: 10.1002/aqc.3576

Sun, J., Tummers, J. S., Galib, S. M., and Lucas, M. C. (2022). Fish community and abundance response to improved connectivity and more natural hydromorphology in a post-industrial subcatchment. Sci. Total Environ. 802:149702. doi: 10.1016/j.scitotenv.2021.149720

Tummers, J. S., Hudson, S., and Lucas, M. C. (2016). Evaluating the effectiveness of restoring longitudinal connectivity for stream fish communities: towards a more holistic approach. Sci. Total Environ. 569-570, 850-860. doi: 10.1016/j. scitotenv.2016.06.207

Conflict of Interest: The authors declare that the research was conducted in the absence of any commercial or financial relationships that could be construed as a potential conflict of interest.

Publisher's Note: All claims expressed in this article are solely those of the authors and do not necessarily represent those of their affiliated organizations, or those of the publisher, the editors and the reviewers. Any product that may be evaluated in this article, or claim that may be made by its manufacturer, is not guaranteed or endorsed by the publisher.

Copyright (c) 2021 Bubb, Birnie-Gauvin, Tummers, Aarestrup, Jepsen and Lucas. This is an open-access article distributed under the terms of the Creative Commons Attribution License (CC BY). The use, distribution or reproduction in other forums is permitted, provided the original author(s) and the copyright owner(s) are credited and that the original publication in this journal is cited, in accordance with accepted academic practice. No use, distribution or reproduction is permitted which does not comply with these terms. 